\title{
Flicker Vision of Selected Light Sources
}

\author{
Przemysław Otomański, Grzegorz Wiczyński, Bartosz Zając \\ Institute of Electrical Engineering and Electronics, Poznan University of Technology, Piotrowo street, No. 3a, 60-965, \\ Poznań, Poland
}

\begin{abstract}
The results of the laboratory research concerning a dependence of flicker vision on voltage fluctuations are presented in the paper. The research was realized on a designed measuring stand, which included an examined light source, a voltage generator with amplitude modulation supplying the light source and a positioning system of the observer with respect to the observed surface. In this research, the following light sources were used: one incandescent lamp and four LED luminaires by different producers. The research results formulate a conclusion concerning the description of the influence of voltage fluctuations on flicker viewing for selected light sources. The research results indicate that LED luminaires are less susceptible to voltage fluctuations than incandescent bulbs and that flicker vision strongly depends on the type of LED source.
\end{abstract}

Keywords: Flicker, light source, voltage fluctuation, power quality.

\section{INTRODUCTION}

Voltage fluctuations influence the state of the supplied loads. Different light sources are most susceptible to fluctuation. Voltage fluctuations can cause flicker. Depending on the variability and type of the light source, flicker can be sensible or visible. With a sufficiently high intensity, flicker can be obnoxious. Nowadays, rooms are lit with incandescent lamps, discharge light sources (including the compact fluorescent lamps) and more and more frequently - LED luminaires (mostly the matrices of LED diodes). Examination of flicker vision requires experimental work using a set of representative light sources, a sufficiently large population of observers and properly set parameters of voltage fluctuation. Currently, there is no available literature to report results of such research. Nevertheless, there are reports of experimental work only for selected groups of light sources and for narrowed set of parameters of voltage fluctuation. Paper [1] presents the influence of modulation with sinusoid signal, only for $60 \mathrm{~W}$ of traditional bulb, on flicker severity, and the modulation range was limited to the frequency of $20 \mathrm{~Hz}$. Work [2] presents the different types of fluorescent lamps with different power, for the case of modulation with voltage signal containing interharmonics of different values. Paper [3] contains the results of research concerning the dependence of flicker vision on the fluctuations of voltage containing interharmonics for a few fluorescent lamps with different types of ballasts.

This paper discusses the results of laboratory research concerning the dependence of flicker vision on voltage fluctuations. The research was conducted on a properly prepared measuring stand, which will be described further.
The following light sources were used in the research: incandescent, and LED luminaires by different manufacturers. The research was conducted for voltage fluctuations reproduced with amplitude modulation (AM) method with modulating signal frequencies in the range of $(0.1-112) \mathrm{Hz}$ in three sub-ranges. The result shows that the whole range of the set modulating frequencies caused flicker. There are no reports of the results of such research yet.

\section{FLICKER SEVERITY CAUSED BY VOLTAGE FLUCTUATION}

Measurement and evaluation of voltage variation in power network is a complex measurement problem. The values of these changes and their type (characteristic) are most frequently caused by the changes of load in power grids. One of the measures defining voltage changes is the voltage fluctuation indices. Voltage fluctuations are, according to [4], "a series of voltage changes or a continuous variation of the rms or peak value of the voltage". Such voltage variation can be characterized by simple parameters: the envelope (the shape of voltage fluctuations), magnitude and frequency (rate). A number of different indicators $\left(P_{s t}\right.$ indicator [5], $\Delta V_{10}$ indicator [6]-[8], voltage fluctuation indices [9]-[10], maximum and minimum rms values [11] and others) describing voltage fluctuations are available in literature. In practice, the following values are most frequently applied: the maximal and minimal rms values of voltages, the indicators of short-time $P_{s t}$ and long-time $P_{l t}$ flicker severity as well as the magnitude and rate of fluctuation. These are some of the most important parameters defining the power quality. Fluctuations are generated by power consumers as a result of the disturbing loads in power grids. Disturbing load is electric 
equipment with repeating sudden state changes. The following loads are considered as disturbing: arc furnaces, welders, pumps, compressors, and rolling mills. In general, these are equipments with significant power in relation to short-circuit power in the point of common coupling.

Voltage fluctuations cause a number of negative influences onto loads. Different types of light sources are among the loads especially susceptible to voltage fluctuations. Flicker is the "impression of unsteadiness of visual sensation induced by a light stimulus whose luminance or spectral distribution fluctuates with time" [12]. Depending on the variability and type of light source flicker can be sensible and visible. Visual perception is a complex process, composed of three stages: the adoption of the light stimulus, its conduction and cognition. Before reaching into our eyes, light passes through the pupil. Under the influence of incident light the pupil dilates and contracts. Voltage fluctuations, and consequently flicker, may cause the motion of the eye [13] and a continuous oscillation of the pupil (hippus) [14]-[16]. This leads to human fatigue, worsening his mood, limiting their visual perception. With a sufficiently high intensity, flicker can be a reason of annoyance. The intensity of flicker to be observed depends on the type of light source, e.g. incandescent bulb, discharge lamps, LED diodes, and on their electrical-optical properties. The results of this research aim to determine the perception threshold of flicker by the participants of the experiment, depending on the voltage fluctuations for selected sources of light.

\section{A. Standard evaluation of flicker severity caused by voltage fluctuation}

As previously mentioned, flicker can cause discomfort in humans. The influence of flicker on an observer, including flicker caused by voltage supplying a light source, is a complex process [15], [17]-[25]. It depends on individual features, observer's condition, environmental conditions, properties of light source, and voltage fluctuations [26]-[28]. To evaluate the flicker severity caused by voltage fluctuations, it is necessary to apply measurement techniques used in social sciences [22], [29]. Such method of evaluating the influence of flicker on human beings is difficult to perform, and therefore, not practically applied. From the technical point of view, it is possible to measure flicker directly (with photometric sensor) in a given point [30]-[38]. This measurement has, however, two fundamental limitations. The measurement result acquired in that way describes flicker only in a certain point of lit surface. Even a slight change in the sensor location can have a significant influence on the result. Gathering representative information on flicker occurrence would require taking measurements in many appropriately selected points. Moreover, even with representative measurement results, the evaluation of flicker severity is not unequivocal. It is caused by individual sensitivity to flicker. The specified difficulties in the evaluation of the influence of flicker on human observer are the reason to search for different measurement methods.

Standard IEC 61000-4-15 [5] specifies how to evaluate the flicker caused by voltage fluctuations. The measure of severity is a pair of indicators: short-time $P_{s t}$ and long-time
$P_{l t}$. Current standards and legal documents defining admissible working conditions of power grids [39] refer to the $P_{s t} / P_{l t}$ indicators. To measure $P_{s t}$ indicator, a meter of flicker (flickermeter) is used. The structure of meter simulates processes occurring in the signal chain: light source - eye brain. According to the standard specification, flickermeter determines the flicker severity caused by the fluctuations of voltage supplying a $60 \mathrm{~W}$ incandescent bulb. It means that for different light sources the results of measuring with flickermeter may not be representative. The reason is that flicker severity caused by the same voltage fluctuations depends on the type of light source used [38], [40]-[50]. The use of the control unit (e.g. dimmer) can also change the susceptibility of incandescent bulbs to the voltage fluctuation [51]-[52]. The long-time flicker indicator $P_{l t}$ is calculated based on a set of values of $P_{s t}$ according to the following formula [5]

$$
P_{l t}=\sqrt[3]{\frac{\sum_{i=1}^{12} P_{s t_{i}}^{3}}{12}}
$$

Voltage variability in power grids is a complex process. The modulation of amplitude with rectangular signal is most frequently used to represent it, according to the dependence below

$$
\begin{aligned}
& u(t)=\sqrt{2} U_{c} \cos \left(2 \pi f_{c} t\right) . \\
& {\left[1+\left(\frac{\Delta U}{U}\right) \frac{1}{2} \operatorname{sign}\left\{\cos \left(2 \pi f_{m} t\right)\right\}\right]}
\end{aligned}
$$

where: $U_{c}$ - declared supply voltage, $f_{c}$ - power frequency, $(\Delta U / U)$ - amplitude modulation depth, $f_{m}$ - frequency of signal modulating the amplitude of voltage $u(t)$.

Assuming that voltage $u(t)$ at the input of flickermeter is determined (2), the value of $P_{s t}$ indicator depends on the $(\Delta U / U)$ modulation depth and $f_{m}$ modulating frequency. In literature, one can frequently find $(\Delta U / U)=\mathrm{f}\left(f_{m}\right)$ for $P_{s t}=1$ $=$ const (i.e. for the state of flicker perceptibility at each frequency by $50 \%$ of the persons tested). Fig. 1 . shows that standard characteristic $(\Delta U / U)=\mathrm{f}\left(f_{m}, P_{s t}=1\right)$ for two nominal voltages: $U_{n}=230 \mathrm{~V} / f_{c}=50 \mathrm{~Hz}$ and $U_{n}=120 \mathrm{~V} / f_{c}=60 \mathrm{~Hz}$ was given.

The characteristic in Fig.1. presents three main local minima. The infimum occurs for $f_{m}=8.8 \mathrm{~Hz}$ and two local extrema for $f_{m}=91.2 \mathrm{~Hz}$ and $f_{m}=108.8 \mathrm{~Hz}$ (for $f_{c}=50 \mathrm{~Hz}$ ). The occurrence of two local minima located close to $f_{m}=100 \mathrm{~Hz}$ is sometimes treated as inconsistent with intuitively interpreted operation of flickermeter signal chain. However, the results of analytical calculations and experiments prove that a full characteristic $(\Delta U / U)=\mathrm{f}\left(f_{m}, P_{s t}=\right.$ const $)$ contains three local extrema [53]. It is also valid for characteristic $P_{s t}=\mathrm{f}\left(f_{m}\right.$, $(\Delta U / U)=$ const $)$, but this one contains three local extrema (a supremum for $\left.f_{m}=8.8 \mathrm{~Hz}\right)$. Characteristic $(\Delta U / U)=\mathrm{f}\left(f_{m}\right.$, $P_{s t}=$ const) in Fig. 1. can be regarded as permissible fluctuation borderline. It means that occurring voltage fluctuations with coordinates $\left(f_{m},(\Delta U / U)\right)$ placed above the borderline can be treated as the occurrence of obnoxious voltage fluctuations. 


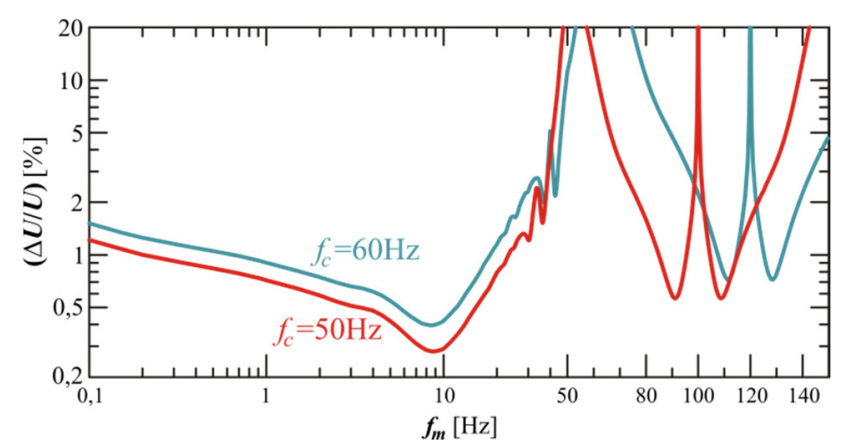

Fig.1. Characteristic $(\Delta U / U)=\mathrm{f}\left(f_{m}, P_{s t}=1\right)$ for $U_{n}=230 \mathrm{~V} / f_{c}=50 \mathrm{~Hz}$ and $U_{n}=120 \mathrm{~V} / f_{c}=60 \mathrm{~Hz}$, amplitude modulation with rectangular signal [53].

\section{TESTING OF FLICKER VISION}

The vision of flicker was tested in laboratory conditions in a performed measuring stand. The results of this type of tests are susceptible to the conditions in which the tests are carried out. Therefore, it is important to determine a procedure for measurements, lab equipment used and environmental conditions.

The main elements of the measuring stand are: a light source supplied from a generator of voltage fluctuations, lit surface (a sheet of white paper), observer, and operator. The use of white, mat sheet of paper eliminated the specular reflection (of light from the source). Therefore, the observer perceived the flicker of scattered light. Particular elements of the stand were placed in a set position. The light source and lit surface were screened from three sides. The fourth side remained open. Therefore, the observer could easily look at the lit surface. During the measurement, the observer's head was immobilized with a fulcrum applied to the forehead. The light source was screened in such a way that the observer could not see it. The intensity of light reaching the stand was regulated with window roller shades. The operator's task was to manage the tests, including the setting of the $f_{m}$ frequency and $(\Delta U / U)$ modulation depth of $\mathrm{AM}$, and to register the value of threshold flicker vision. The observer's tasks were to focus on the lit surface and to inform the operator when flicker was perceived. A simplified structure of the measuring stand to test flicker vision was shown in Fig. 2.

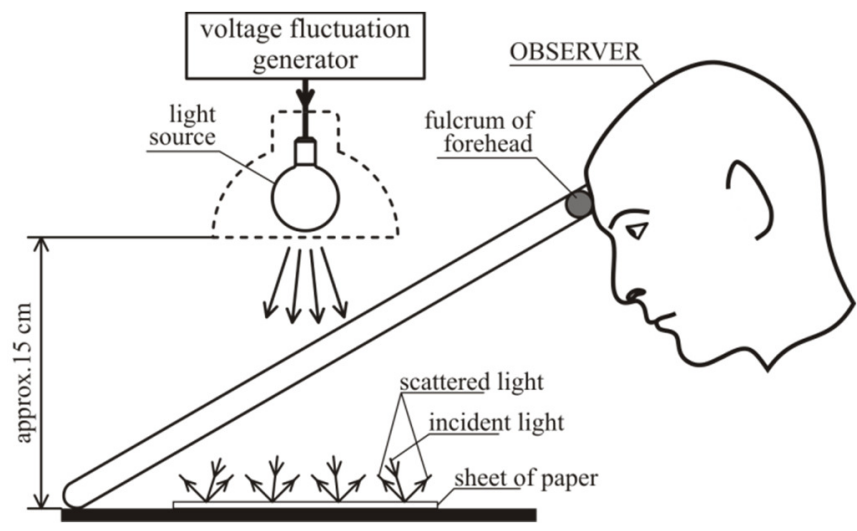

Fig.2. A simplified structure of the measuring stand to test flicker vision.
To generate flicker, a light source supplied from a generator of voltage fluctuations was applied. Five light sources available in the market were applied in the tests: an incandescent bulb with (electric) power of $60 \mathrm{~W}$ as well as four LED luminaires: LEDARE, TB, VAKOSS and Samsung. Table 1. gives a statement of basic parameters of these light sources.

Table 1. Statement of basic parameters of the light sources applied in the tests.

\begin{tabular}{|c|c|c|c|}
\hline No. & $\begin{array}{c}\text { Description of light } \\
\text { sources }\end{array}$ & $\begin{array}{c}\text { Electric } \\
\text { power }\end{array}$ & $\begin{array}{c}\text { Luminous } \\
\text { flux }\end{array}$ \\
\hline 1 & Incandescent bulb & $60 \mathrm{~W}$ & $740 \mathrm{~lm}$ \\
\hline 2 & LEDARE, white 2700K & $10 \mathrm{~W}$ & $600 \mathrm{~lm}$ \\
\hline 3 & TB LED, neutral white & $9 \mathrm{~W}$ & $800 \mathrm{~lm}$ \\
\hline 4 & $\begin{array}{c}\text { VAKOSS LED, } \\
\text { white 2600K }\end{array}$ & $12 \mathrm{~W}$ & $960 \mathrm{~lm}$ \\
\hline 5 & $\begin{array}{c}\text { Samsung LED, } \\
\text { warm white }\end{array}$ & $6 \mathrm{~W}$ & $810 \mathrm{~lm}$ \\
\hline
\end{tabular}

The conducted laboratory experiments show that for smaller luminous flux the flicker vision is more intense. The tests performed (Table 1.) did not provide the same flux value. However, it was assumed that these differences would not significantly affect flicker vision.

The order of light sources in Table 1. is not identical with the denotations applied in the part of the paper presenting the test results. During the tests, the occurrence of flicker vision for generated voltage fluctuations was not found for one of the LED sources. Therefore, in the presentation of flicker test results this light source was omitted. To generate supply voltage fluctuations, given with dependence (2), light sources with nominal voltage $U_{n}=230 \mathrm{~V}$, a system composed of two main blocks was constructed: function generator Agilent 33512 [54] and generator - calibrator Chroma 61502 [55] (taking the role of power amplifier). A block diagram of the voltage fluctuation generator with added control meters devoted to measure voltage $u(t)$, was shown in Fig.3.

The form of time waveform $u(t)$, according to formula (2), was determined with the settings of generator Agilent 33512. The parameters of voltage fluctuations were set by means of the values of $(\Delta U / U)$ modulation depth and $f_{m}$ frequency of AM with a rectangular signal. The end result of the testing of flicker vision is a set of threshold values $(\Delta U / U)=\mathrm{f}\left(f_{m}\right)$. In order to determine a threshold value for a set frequency $f_{m}$, a minimal value $(\Delta U / U)=0.1 \%$ was set preliminarily. Then, the modulation depth was increased as long as flicker was noticed (seen visible). Modulation depth $(\Delta U / U)$, corresponding to the detection of flicker, was regarded as the threshold value. For the purpose of these tests, two sets of frequency $f_{m}$ were assumed: separately for the incandescent light source and for the LED sources. Taking into account the three extrema of characteristic $(\Delta U / U)=\mathrm{f}\left(f_{m}, P_{s t}=1\right)$ (Fig.1.), frequency $f_{m}$ was divided into three sub-ranges (in relation to the power frequency $\left.f_{c}\right)$ : $\mathbf{L}\left(f_{m}<f_{c}\right)$, H1 $\left(f_{c}<f_{m}<2 f_{c}\right)$ and $\mathbf{H 2}\left(2 f_{c}<f_{m}<3 f_{c}\right)$. Full set of $f_{m}$ frequencies applied in the tests was provided in Table 2. 


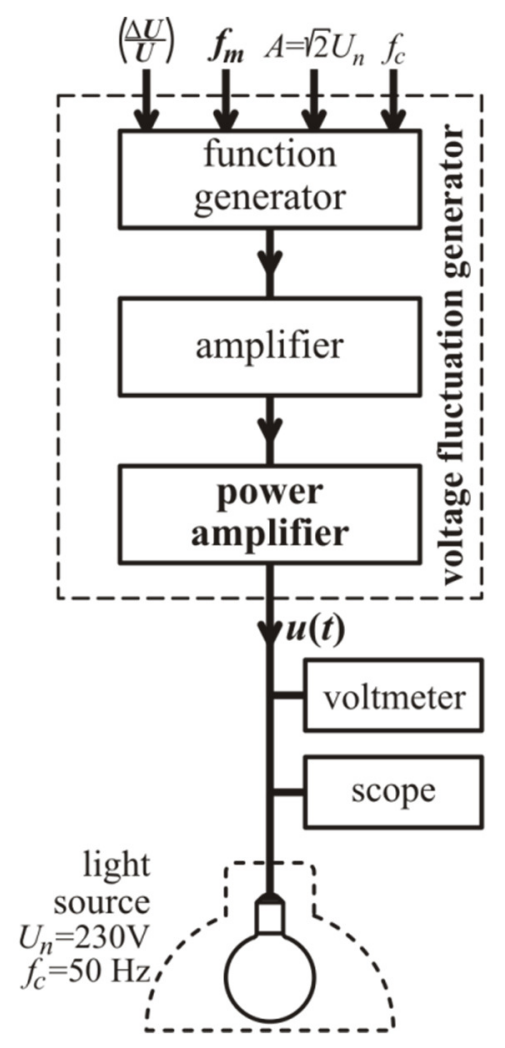

Fig.3. A block diagram of the voltage fluctuation generator with nominal voltage $U_{n}=230 \mathrm{~V}$; function generator - Agilent 33512 , amplifier - voltage amplifier with a gain of $4.93 \mathrm{~V} / \mathrm{V}$ (with op-amp), power amplifier - Chroma 61502, voltmeter - Agilent 34401A, scope - TPS 2024.

Table 2. Statement of $f_{m}$ frequencies applied in the tests of flicker vision.

\begin{tabular}{|c|c|c|c|}
\hline \multirow{2}{*}{$\begin{array}{c}\text { Light } \\
\text { source }\end{array}$} & \multicolumn{3}{|c|}{ Sub-ranges of $\boldsymbol{f}_{\boldsymbol{m}}[\mathrm{Hz}]$} \\
\cline { 2 - 4 } & $\mathbf{L}$ & $\mathbf{H 1}$ & $\mathbf{H 2}$ \\
\hline & $0.1,0.316,0.5$, & 88,90, & 104,106, \\
& $0.916,2,4,6$, & $91.2,94$, & 108.8, \\
incandescent & $7,8.4,8.8,9.2$, & 96 & 110,112 \\
bulb & $10,11,12$, & & \\
& $13.5,16,20$, & & \\
& $25,33.33$ & & \\
\hline & $0.1,1,2,5,8.8$, & 88,90, & 104,106, \\
LEDs & $10,12,16,25$ & $91.2,94$, & 108.8, \\
& & 96 & 110,112 \\
\hline
\end{tabular}

A group of 10 volunteers was acquired for the tests -5 females and 5 males. The tests were carried out in the afternoon (after the volunteers went back from work). Each observer consumed a total test time of 40-50 min. During that time, the observer was staring at a white sheet focusing on the detection of flicker. After some time, it causes fatigue to the observers. The impact of fatigue on the measurement results is not part of the research. However, two observers were twice tested and it obtained converge results from the first and second tests.
A summary of selected information about the observers is given in Table 3. A group of "older people" (4 observers aged between 51 and 53 years) and a group of "younger people" ( 6 observers aged between 21 and 31 years) were distinguished.

Table 3. Summary of the observers participating in the tests.

\begin{tabular}{|c|c|c|c|}
\hline No. & Sex & Age & Age group \\
\hline 1 & male & 53 & "older people" \\
\hline 2 & male & 53 & "older people" \\
\hline 3 & male & 31 & "younger people" \\
\hline 4 & male & 26 & "younger people" \\
\hline 5 & male & 21 & "younger people" \\
\hline 6 & female & 25 & "younger people" \\
\hline 7 & female & 26 & "younger people" \\
\hline 8 & female & 30 & "younger people" \\
\hline 9 & female & 51 & "older people" \\
\hline 10 & female & 52 & "older people" \\
\hline
\end{tabular}

The values obtained in the measurements are binary: the vision of flicker or the lack of flicker vision. Therefore, it is difficult to use statistical tools like the determination of correlation coefficient. That is why the authors did not perform a deeper statistical analysis.

Ten volunteers participating in the tests are not a large statistical sample. However, in the authors' opinion, the results of measurement obtained for such population are sufficiently representative to formulate preliminary conclusions.

\section{RESULTS OF EXPERIMENTS ON FLICKER VISION}

The result of the tests was a total of 860 threshold values. Fig.4. presents a characteristic $(\Delta U / U)=\mathrm{f}\left(f_{m}\right)$ which plotted all the threshold values (for 10 observers and 4 light sources). To make the analysis of the characteristic easier, the permissible fluctuation borderline from Fig.1. was added.

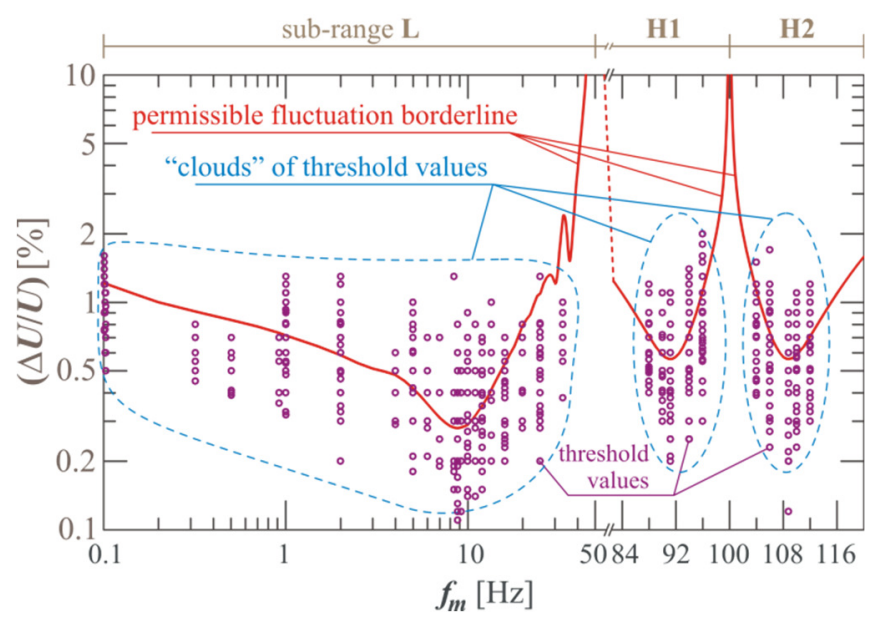

Fig.4. Characteristic $(\Delta U / U)=\mathrm{f}\left(f_{m}\right)$ with plotted all the threshold values and the standard permissible fluctuation borderline marked. 
In the characteristic depicted in Fig.4. one can see "clouds" of points representing the threshold values. The forms of "clouds" of points and the permissible fluctuation borderline indicate a certain degree of similarity. However, the scattered threshold values for particular frequencies $f_{m}$ suggest that the flicker vision depends not only on frequency $f_{m}$, but also on other factors. Therefore, further part of the paper will present the measurement results with regard to the type of source light as well as the age and gender of the observers. As mentioned previously, the permissible fluctuation borderline from Fig.1. describes the perception of flicker for an incandescent source with a power of $60 \mathrm{~W}$. It is justified, then, to compare the obtained results of testing flicker vision with the standard permissible fluctuation borderline.

\section{A. Flicker vision of light emitted by incandescent bulb of $60 \mathrm{~W}$}

Because of the availability of standard permissible fluctuation borderline, the testing of flicker vision of light emitted by an incandescent source of $60 \mathrm{~W}$ is especially interesting. Fig.5. presents the threshold values for flicker vision for incandescent light source of $60 \mathrm{~W}$. To make the interpretation of the acquired test results easier, the values of modulation depth $(\Delta U / U)$ for a particular person and for all frequencies $f_{m}$ were averaged in the diagram. According to [5], a median was assumed as a feature in the averaging process. Median is widely applied in statistics because it is much more resistant to outliers than arithmetic mean. Its sample value is a consistent and asymptotically unbiased estimator of the expected value in a population for an arbitrary distribution. In all characteristics presented in further parts of the paper, all presented waveforms are determined as averaged values for a tested person with the use of median.

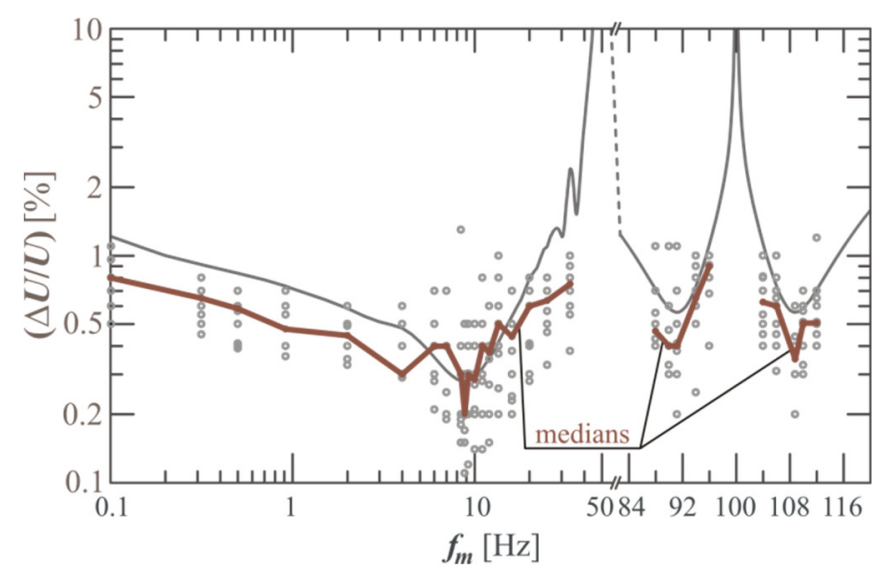

Fig.5. Characteristic $(\Delta U / U)=\mathrm{f}\left(f_{m}\right)$ with threshold and median values for incandescent bulb of $60 \mathrm{~W}$ and marked permissible fluctuation borderline.

The "clouds" of threshold values in Fig.5. are more similar to the permissible fluctuation borderline than in Fig.4. The location of middle values for most frequencies $f_{m}$ approximates the form of permissible fluctuation borderline.
The consistency of frequencies corresponding to three local extrema of middle values and permissible fluctuation borderline can be noticed. In order to make a wider comparative analysis, the volunteers who participated in the experiment were divided according to gender and age criteria. The group of observers consisted of 5 females and 5 males. Fig.6. shows the threshold values of flicker vision for incandescent source of $60 \mathrm{~W}$, separately for women and men.

When comparing the characteristics from Fig.6., higher sensitivity to flicker vision can be noticed for female observers. It occurs in three sub-ranges of frequency $f_{m}$. Moreover, a group of "younger people" -6 observers, and a 4-person group of "older people" was formed. A similar analysis was performed as in the case of gender, using as a criterion the age of tested persons. In Fig.7. the threshold values of flicker vision are provided separately for the group of "younger observers" and the group of "older observers".

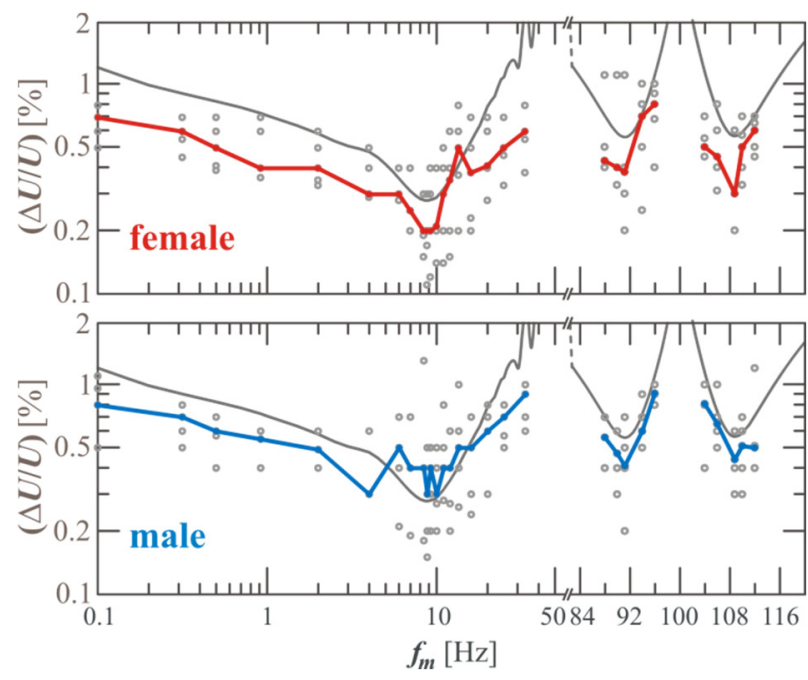

Fig.6. Characteristic $(\Delta U / U)=\mathrm{f}\left(f_{m}\right)$ with threshold and median values for incandescent bulb of $60 \mathrm{~W}$; separately for female and male observers.

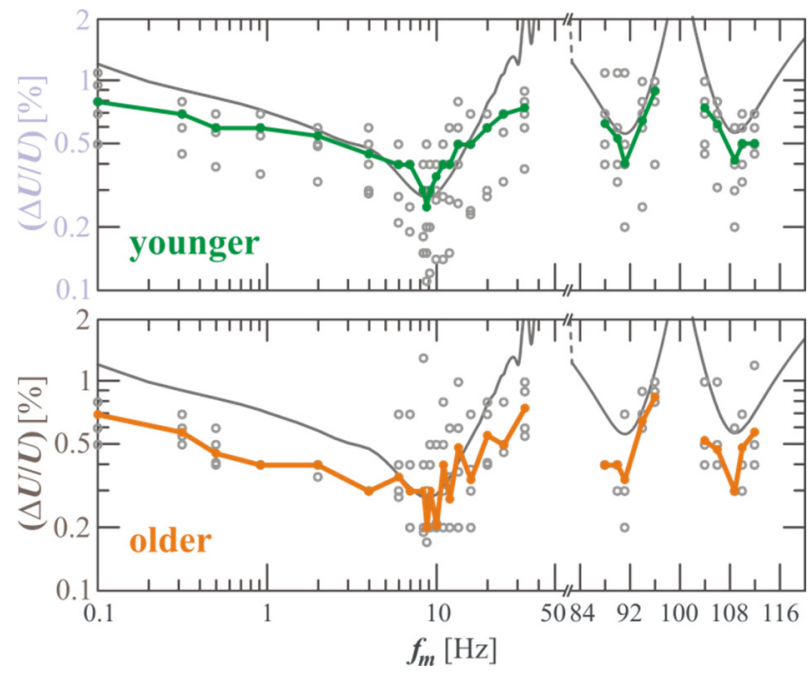

Fig.7. Characteristic $(\Delta U / U)=\mathrm{f}\left(f_{m}\right)$ with threshold and median values for incandescent bulb of $60 \mathrm{~W}$; separately for younger and older people. 
The test results suggest that older people are more susceptible to flicker of light coming from the incandescent source. Higher susceptibility of older people can be noticed in three sub-ranges of frequency $f_{m}$.

\section{B. Flicker vision of light emitted by LED luminaires}

Four different LED luminaires were used in the tests. As mentioned before, for one of these sources, flicker was not perceived. At the same time, there was a reference to the results of testing three light sources denoted as LED1, LED2 and LED3, presented below. For comparison, the results of tests for incandescent bulb of $60 \mathrm{~W}$ were added. Fig.8. shows the median values of thresholds of flicker vision for sources LED1-LED3 and for a $60 \mathrm{~W}$ incandescent bulb.

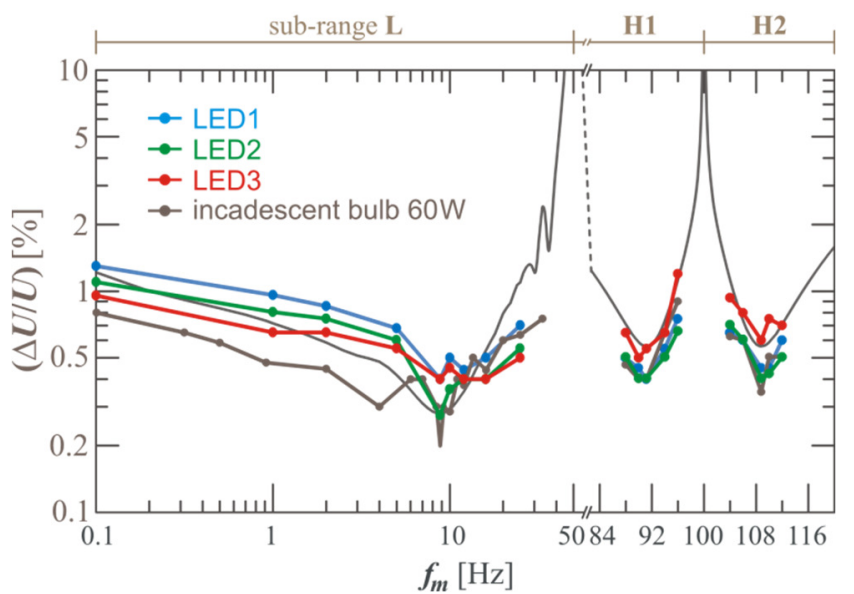

Fig.8. Characteristic $(\Delta U / U)=\mathrm{f}\left(f_{m}\right)$ with median values of vision thresholds of flicker for LED1 - LED3 luminaires and $60 \mathrm{~W}$ incandescent bulb for all observers.

After comparing the test results for different light sources, it can be noticed that for frequency $f_{m}<8.8 \mathrm{~Hz}$, LED sources are less susceptible to voltage fluctuations than incandescent bulbs. Lower susceptibility of LED sources is consistent with intuitive predictions. The reason is that LED luminaires consist of semiconductor light sources (LED diodes) and power supply unit (AC adapter). The susceptibility of LED sources to voltage fluctuations is decided by the properties of supplier (usually the capacity of filter capacitor of AC adapter) [56]-[58]. LED sources without an AC adapter (e.g. LED diodes supplied with a resistor) are the sources of light most susceptible to voltage fluctuations. When analyzing the characteristic in Fig.8. it is easy to notice that in sub-range L, LED3 is the most susceptible from among all the LED sources. Instead, in sub-ranges $\mathrm{H} 1$ and $\mathrm{H} 2$, this source is the least susceptible to voltage fluctuations. The light spectrum can influence flicker vision. It means that for the same supplier and different LED diodes, flicker vision can also be different.

A comparative analysis of characteristics $(\Delta U / U)=\mathrm{f}\left(f_{m}\right)$ was also performed for two exemplary LED luminaires, denoted as LED1 and LED3 with regard to the criterion of gender and age. Fig.9. shows the median values of flicker vision (perception) thresholds for sources LED1 and LED3, separately for female and male observers.

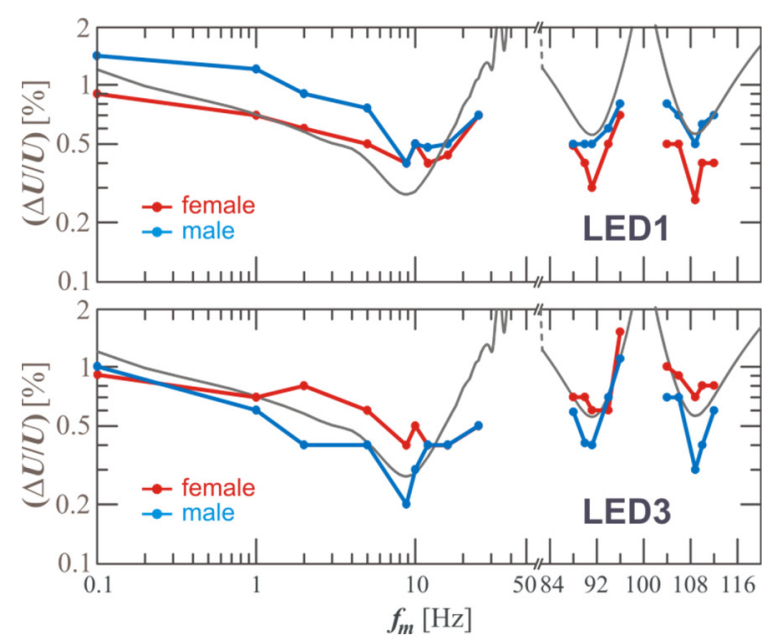

Fig.9. Characteristic $(\Delta U / U)=\mathrm{f}\left(f_{m}\right)$ with median values of flicker vision thresholds for LED1 and LED3 luminaires; separately for female and male observers.

Fig.10. presents the median values of flicker vision thresholds separately for the group of "younger observers" and the group of "older observers".

Characteristics from Fig.10. show that flicker vision for LED1 and LED3 sources is slightly dependent on the observer's age. In sub-ranges $\mathrm{H} 1$ and $\mathrm{H} 2$ of frequency $f_{m}$ the group of younger observers detects flicker slightly easier. In sub-range $\mathrm{L}$ it is difficult to indicate a group of observers more susceptible to flicker for LED sources.

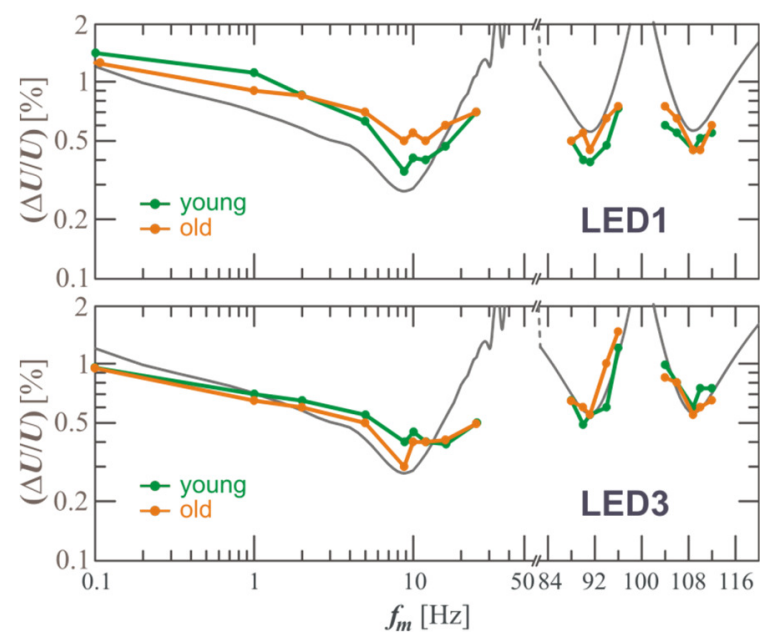

Fig.10. Characteristic $(\Delta U / U)=\mathrm{f}\left(f_{m}\right)$ with median values of flicker vision thresholds for LED1 and LED3 luminaires; separately for younger and older observers.

In Fig.4. to Fig.10, a permissible fluctuation borderline is marked ("the reference curve"). This borderline reconstructs the perceptibility threshold of flicker severity found at each frequency by $50 \%$ of the persons tested for a coiled filament gas-filled lamp of $60 \mathrm{~W}$. It is important to emphasize the difference between the perceptibility of flicker severity and the vision of flicker. The medium curve reproduces the threshold of flicker vision. Not every visible flicker is severe. In addition, not every severe flicker of light is visible. From 
the previous studies, it is clear that the threshold of flicker vision (for a coiled filament gas-filled lamp of $60 \mathrm{~W}$ ) is lower than the threshold of flicker severity, regardless of the parameters of the observer.

\section{CONCLUSIONS}

The paper presents the results of laboratory tests of the dependence of flicker vision on the fluctuations of voltage supplying a selected light source. One incandescent source and four LED sources (different types) were applied in the tests. The measurements were carried out on a properly prepared position measuring stand, on a group of 10 observers. For the purpose of the analysis, the collected test results were divided according to light source type as well as the age and the gender of the observers. During the test while using one of the LED sources, the occurrence of flicker was not found. Thus, only the test results of three LED sources were presented. The tests were carried out in a full frequency range of modulating signal $0<f_{m}<3 f_{c}$ generating flicker. There are no reports of test results in the full modulating frequency range. In the available literature, the testing of flicker vision was limited, without any justification, to the first sub-range of frequency $0<f_{m}<f_{c}$. Analyzing the obtained measurement results, the following conclusions were formulated.

For incandescent light sources, there is a high conformity of frequencies corresponding to local extrema of median values with the permissible fluctuation borderline. When comparing the obtained results according to gender, it is possible to conclude that women are more susceptible to flicker vision than men in all the three sub-ranges of frequency. The results of the tests considering age criterion indicate that the group of "older people" is (only slightly) more susceptible to flicker in comparison with the group of "younger people".

After comparing the test results for different light sources, it can be noticed that, for most part of the L sub-range and whole $\mathrm{H} 1$ and $\mathrm{H} 2$ sub-ranges, LED sources are less susceptible to voltage fluctuations than incandescent bulbs. Lower susceptibility to voltage fluctuations of LED sources is caused by the fact that the properties of such light sources are decided by the properties of supplier of such source. When comparing the LED sources among one another, one can notice that in sub-range $L$ the most susceptible source is LED3, and in sub-ranges $\mathrm{H} 1$ and $\mathrm{H} 2$ this source is the least susceptible to voltage fluctuations. In the case of comparative tests of light sources denoted as LED1 and LED3, when dividing the observers according to age and gender, it is possible to formulate two conclusions. Using the criterion of gender, it is possible to state that for LED1 source the group of female observers is more susceptible, and for LED3 source the group of male observers has a higher susceptibility to voltage fluctuations. After the analysis of the obtained results for the groups of "younger people" and "older people", it is possible to conclude that the obtained characteristics do not allow to point out an unequivocal group of observers more susceptible to flicker.

The research results provided in this paper indicate that flicker vision depends on the type of LED source. Therefore, it is justified to extend the range of experiments for a more numerous population of observers with the use of a bigger number of light sources. The results of tests carried out so far were cognitive. One can, however, perceive their potential utility benefits. For example, trying to decrease the flicker severity, caused by voltage fluctuations, one can replace different light sources with LED sources. However, the susceptibility of LED sources to voltage fluctuations depends on the type. In order to decrease flicker as much as possible, it is necessary to select an appropriate type of LED source. It is also necessary to light the work place in which women dominate with different LED light sources than in the case of lightning the work place for men.

\section{REFERENCES}

[1] Braun, J., Perera, S., Gosbell, V. (2005). Design of light chamber for the characterisation of flicker behavior of lamps. In Australasian Universities Power Engineering Conference, Hobart, Australia, 1-6.

[2] Chen, S., Heah, M.Y., Then, A.B., Foo, M.K. (2008). Automatic evaluation of flickering sensitivity of fluorescent lamps caused by interharmonic voltages. In XIII International Conference on Harmonics and Quality of Power, Wollongong, Australia, 1-6.

[3] Drapela, J., Kratky, M., Weidinger, L., Zavodny, M. (2005). Light flicker of fluorescent lamps with different types of ballasts caused by interharmonics. In 2005 IEEE Russia Power Tech, St. Petersburg, Russia, 1-7.

[4] International Electrotechnical Commission. (2016). Voltage fluctuation. IEV number 161-08-05. http://www.electropedia.org.

[5] International Electrotechnical Commission. (2010). Testing and measurement techniques - Flickermeter Functional and design specifications. IEC 61000-415:2010.

[6] Aoki, M. (1980). Standard method for measurement of voltage fluctuations. In $9^{\text {th }}$ International Congress UIE, Cannes, France, 3-12.

[7] Hong, Y.-Y., Lee, L.-H. (1999). Analysis of equivalent $10 \mathrm{~Hz}$ voltage flicker in power systems. IEE Proceedings - Generation, Transmission and Distribution, 146 (5), 447-452.

[8] Wiczyński, G. (2017). Model of $D V_{10}$-meter signal chain for periodic voltage fluctuation. Measurement, 93, 224-231.

[9] Owen, E.L. (1994). Power disturbance and power quality - light flicker voltage requirements. In Conference Record of the 1994 IEEE Industry Applications Society Annual Meeting, Denver, USA, Vol. 3, 2303-2309.

[10] Wiczyński, G. (2017). Estimation of $P_{s t}$ indicator values on the basis of voltage fluctuation indices. IEEE Transactions on Instrumentation and Measurement, 66 (8), 2046-2055.

[11] Otomański, P, Wiczyński, G. (2011). The usage of voltage and current fluctuation for localization of disturbing loads supplied from power grid. Przeglad Elektrotechniczny, 87 (1), 107-111. 
[12] International Electrotechnical Commission. (2016). Flicker, IEV number 845-02-49.

http://www.electropedia.org.

[13] Lehman, B., Wilkins, A.J. (2014). Designing to mitigate effects of flicker in LED lighting: Reducing risks to health and safety. IEEE Power Electronics Magazine, 1 (3), 18-26.

[14] Howarth, P., Heron, G., Greenhouse, D.S., Bailey, I.L., Berman, S.M. (1993). Discomfort from glare: The role of pupillary hippus. Lighting Research \& Technology, 25 (1), 37-42.

[15] Peretto, L., Rovati, L., Salvatori, G., Tinarelli, R., Emanuel, A.E. (2007). A measurement system for the analysis of the response of the human eye to the light flicker. IEEE Transactions on Instrumentation and Measurement, 56 (4), 1384-1390.

[16] Stone, P.T. (2009). A model for the explanation of discomfort and pain in the eye caused by light. Lighting Research \& Technology, 41 (2), 109-121.

[17] Emanuel, A.E., Peretto, L. (2004). A simple lamp-eyebrain model for flicker observations. IEEE Transactions on Power Delivery, 19 (4), 1308-1313.

[18] Peretto, L., Emanuel, A.E. (1997). A theoretical study of the incandescent filament lamp performance under voltage flicker. IEEE Transactions on Power Delivery, 12 (1), 279-288.

[19] Peretto, L., Pivello, E., Tinarelli, R., Emanuel, A.E. (2007). Theoretical analysis of the physiologic mechanism of luminous variation in eye-brain system. IEEE Transactions on Instrumentation and Measurement, 56 (1), 164-170.

[20] Masi, M.G., Peretto, L., Tinarelli, R., Rovati, L. (2008). Modeling of the physiological behavior of human vision system under flicker condition. In XIII International Conference on Harmonics and Quality of Power, Wollongong, Australia, 1-6.

[21] Musiał, E. (2005). Podstawowe pojęcia techniki oświetleniowej. Biuletyn SEP INPE, 75. (in Polish)

[22] Kim, C.B., Mayer, M.J. (1994). Foveal flicker sensitivity in healthy aging eyes. II. Cross-sectional aging trends from 18 through 77 years of age. Journal of the Optical Society of America, 11 (7), 1958-1969.

[23] Rashbass, C. (1970). The visibility of transient changes of luminance. Journal of Physiology, 210 (1), 165-186.

[24] Sokol, S., Tiggs, L.A. (1971). Electrical and psychophysical responses of the human visual system to periodic variation of luminance. Investigative Ophthalmology, 10 (3), 171-180.

[25] Wilkins, A., Veitch, J., Lehman, B. (2010). LED lighting flicker and potential health concerns: IEEE standard PAR1789 update. In IEEE Energy Conversion Congress and Exposition, Atlanta, USA, 171-178.

[26] Peretto, L., Riva, C.E., Rovati, L., Salvatori, G., Tinarelli, R. (2009). Analysis of the effects of flicker on the blood-flow variation in the human eye. IEEE Transactions on Instrumentation and Measurement, 58 (9), 2916-2922.
[27] Cai, R., Cobben, J., Myrzik, J., Blom, J., Kling, W. (2008). New flicker weighting curves for different lamp types based on the lamp light spectrum. In XIII International Conference on Harmonics and Quality of Power, Wollongong, Australia, 1-6.

[28] Walker, M. (1979). Electric utility flicker limitations. IEEE Transactions on Industry Applications, IA-15 (6), 644-655.

[29] Culham, J.C., Kline, D.W. (2002). The age deficit on photopic counterphase flicker: Contrast, spatial frequency, and luminance effects. Canadian Journal of Experimental Psychology, 56 (3), 177-186.

[30] Gallo, D., Landi, C., Pasquino, N. (2006). Design and calibration of an objective flickermeter. IEEE Transactions on Instrumentation and Measurement, 55 (6), 2118-2125.

[31] Gallo, D., Landi, C., Pasquino, N. (2004). An instrument for objective measurement of light flicker. Measurement, 41 (3), 334-340.

[32] Cai, R., Cobben, J., Myrzik, J., Blom, J., Kling, W. (2009). Flicker responses of different lamp types. IET Generation, Transmission \& Distribution, 3 (9), 816824.

[33] Cai, R. (2009). Working out a model and an analysis of metrological properties of a digital flickermeter. $\mathrm{Ph} . \mathrm{D}$. dissertation, Eindhoven University of Technology, Eindhoven, Netherlands.

[34] Shareef, H., Mohamed, A., Mohamed, K. (2010). Sensitivity of compact fluorescent lamps during voltage sags: An experimental investigation. WSEAS Transactions on Power Systems, 1 (5), 22-31.

[35] Masi, M.G., Peretto, L., Tinarelli, R., Rovati, L. (2011). Assessment of human annoyance under flicker condition. In 2011 IEEE Instrumentation and Measurement Technology Conference, Binjiang, China, $1-5$.

[36] Chmielowiec, K. (2011). Flicker effect on different types of light sources. In $11^{\text {th }}$ International Conference on Electrical Power Quality and Utilisation, Lisbon, Portugal, 1-6.

[37] Azcarate, I., Gutierrez, J., Saiz, P., Lazkano, A., Leturiondo, L., Redondo, K. (2014). Flicker characteristics of efficient lighting assessed by the IEC flickermeter. Electric Power Systems Research, 107, 21-27.

[38] Azcarate, I., Gutierrez, J., Lazkano, A., Saiz, P., Redondo, K., Leturiondo, L. (2014). Experimental study of the response of efficient lighting technologies to complex voltage fluctuations. Electrical Power and Energy Systems, 63, 499-506.

[39] International Electrotechnical Commission. (2015). Testing and measurement techniques - Power Quality Measurement Methods. IEC 61000-4-30:2015.

[40] de Lange Dzn, H. (1958). Research into the dynamic nature of the human fovea - cortex systems with intermittent and modulated light. II. Phase shift in brightness and delay in color perception. Journal of the Optical Society of America, 48 (11), 784-789. 
[41] Kelly, D.H. (1961). Visual responses to time-dependent stimuli. I. Amplitude sensitivity measurements. Journal of the Optical Society of America, 51 (4), 422-429.

[42] Andersson, N., Sandstrom, M., Berglund, A., Hansson, K. (1994). Amplitude modulation of light various sources. Lighting Research and Technology, 26 (3), 157-160.

[43] Veitch, J.A., McColl, S.L. (1995). Modulation of fluorescent light: Flicker rate and light source effects on visual performance and visual comfort. Lighting Research and Technology, 27 (4), 243-256.

[44] Carrillo, C., Cidrás, J. (2001). Fluorescent lamp modelling for voltage fluctuations. European Transactions on Electrical Power, 11 (2), 119-127.

[45] Gomez, J., Morcos, M. (2002). Flicker measurement and light effect. IEEE Power Engineering Review, 22 (11), 11-15.

[46] Rong, C., Cobben, J.F.G., Myrzik, J.M.A., Blom, J.H., Kling, W.L. (2007). Flickermeter used for different types of lamps. In $9^{\text {th }}$ International Conference on Electrical Power Quality and Utilisation, Barcelona, Spain, 1-6.

[47] Manana, M., Ortiz, A., Renedo, C., Perez, S., Delgado, F., Azcondo, F.J., Diaz, F.J., Branas, C., Casanueva, R. (2007). Comparison of flicker sensitivity in HPS lamps. In International Symposium on Industrial Electronics, Vigo, Spain, 3002-3007.

[48] Wie, Z., Watson, N.R., Frater, L.P. (2008). Modelling of compact fluorescent lamps. In XIII International Conference on Harmonics and Quality of Power, Wollongong, Australia, 1-6.

[49] Kim, T., Rylander, M., Powers, E.J., Grady, W.M., Arapostathis, A. (2008). LED lamp flicker caused by interharmonics. In IEEE International Instrumentation and Measurement Technology Conference, Victoria, Canada, 1-6.
[50] Koponen, P, Hansen, H., Bollen, M. (2015). Interharmonics and light flicker. In $23^{\text {rd }}$ International Conference on Electricity Distribution, Lyon, France, 1/5-5/5.

[51] Wang, C. (2008). Flicker-insensitive light dimmer for incandescent lamps. IEEE Transactions on Industrial Electronics, 55 (2), 767-772.

[52] Sharma, H., Sharp, F., McGranaghan, M. (2013). Flicker voltage fluctuation response of modern lamps including those with dimmable capability and other low voltage sensitive equipment. In $22^{\text {nd }}$ International Conference on Electricity Distribution, Stockholm, Sweden, 1-4.

[53] Wiczyński, G. (2008). Sectional approximation of the flickermeter transformation characteristic for a sinusoidal modulating signal. IEEE Transactions on Instrumentation and Measurement, 57 (10), 23552363.

[54] Agilent Technologies, Inc. (2012). Agilent 33500 Series Waveform Generator - Operating and Service Guide.

[55] Chroma ATE Inc. (2004). Programmable AC Source 61501/61502/61503/61504 User's Manual.

[56] Uddin, S., Shareef, H., Mohamed, A. (2013). Power quality performance of energy-efficient low-wattage LED lamps. Measurement, 46 (10), 3783-3795.

[57] Zhang, R., Chung, H.S. (2014). A triac-dimmable LED lamp driver with wide dimming range. IEEE Transactions on Power Delivery, 29 (3), 1434-1446.

[58] Shrivastava, A., Singh, B., Pal, S. (2015). A novel wallswitched step-dimming concept in LED lighting systems using PFC zeta converter. IEEE Transactions on Industrial Electronics, 62 (10), 6272-6283

Received April 27, 2017. Accepted September 22, 2017. 